\title{
Subseasonal-to-seasonal (S2S) forecasts with CNRM-CM: a case study on the July 2015 West-European heat wave
}

\author{
Constantin Ardilouze, Lauriane Batté, and Michel Déqué \\ CNRM UMR 3589, Météo-France/CNRS, Toulouse, France \\ Correspondence to: Constantin Ardilouze (constantin.ardilouze@meteo.fr)
}

Received: 12 January 2017 - Revised: 3 April 2017 - Accepted: 7 April 2017 - Published: 5 May 2017

\begin{abstract}
An intense heat wave struck West Europe in early July 2015. The degree of anticipation of that event is assessed through the new CNRM near-real time subseasonal to seasonal forecast system. A warm anomaly over France was detected for the first week of July in all the successive forecasts issued in June, even up to one month ahead. On the other hand, the positive $500 \mathrm{hPa}$ geopotential anomaly observed during that period was little anticipated. Despite the limited skill of the forecast system beyond twelve days, the relatively successful anticipation of that event pleads for a predictability study based on a multi-system assessment.
\end{abstract}

\section{Introduction}

In the context of global warming, changes in extreme climate events in terms of severity, frequency and duration are expected (Perkins, 2015). In particular, an increase of these characteristics is robustly projected over Europe for heat waves (Schoetter et al., 2014). Since the early 2000's, a number of them has affected various parts of Europe, with significant socio-economic impacts such as heat-related mortality and financial losses due to crop failure or wild fire damages. The disastrous consequences of the deadly heat wave that struck West Europe in August 2003 made the predictability of these high-impact events a matter of the utmost expectations. However, the predictability horizon of numerical weather prediction systems is limited to a dozen of days because of the chaotic essence of the atmosphere (Lorenz, 1963). Further anticipation would improve both preparedness and organization of civil protection and public services dedicated to managing extreme long-lasting high-impact climate events such as heat waves (Brunet et al., 2010). There is no consensus on the definition of a heat wave, even though it is commonly characterized as temperature exceeding a given threshold for several consecutive days (Ouzeau et al., 2016). Depending on the applications and impacts considered, definitions rely either on minimum and/or maximum daily temperature or mean temperature percentiles, with or without re- moving a seasonal cycle (Barbier et al., 2017). In any case, the requirement for a warm spell to last at least (typically) 3 to 5 days (Perkins et al., 2015) in the various operational definitions implies that such an event would translate into pronounced higher-than-average weekly mean temperature anomalies. Sub-seasonal prediction systems are therefore suitable for anticipating such events since they are tailored to forecast weekly anomalies up to one or two months ahead. In July 2015, a three-week long heat wave affected parts of West Europe, including France, Spain, Switzerland and Germany where a few record-breaking temperatures were reached. The present study addresses the predictability of this warm event based on the new CNRM near-real time subseasonal to seasonal (S2S) forecast system, designed in the framework of the World Weather Research Programme/World Climate Research Programme (WWRP/WCRP) initiative on S2S prediction (Brunet et al., 2010; Robertson et al., 2015).

The first section of this paper describes the main features of the forecast system and provides details about the metrics used. Results on the heat wave anticipation based on forecasts are detailed in the following section. The last section provides a discussion on these results and a conclusion. 


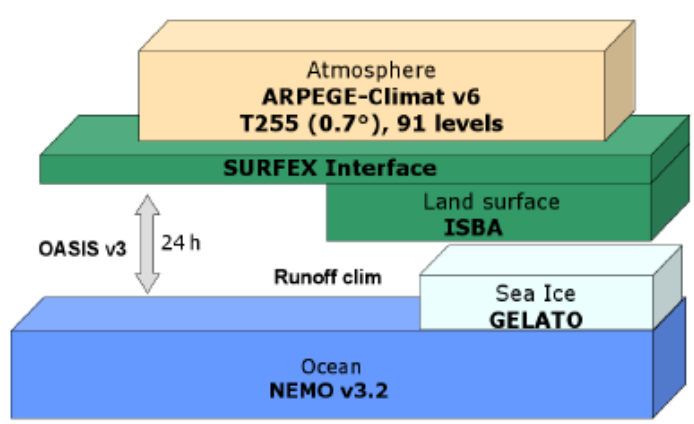

Figure 1. CNRM-CM S2S forecast system components.

\section{Experimental design}

\subsection{CNRM-CM subseasonal forecast system}

The CNRM-CM S2S forecast system relies on a global coupled model (Voldoire et al., 2013) similar to that used for Météo-France operational seasonal forecast system 5. The horizontal resolution is about $0.7^{\circ}$ for the atmospheric and surface component ARPEGE-SURFEX and $1^{\circ}$ for the oceansea-ice model NEMO-GELATO with a refinement in the tropical oceans (Fig. 1). The coupling frequency is $24 \mathrm{~h}$. This system provides routinely near-real time 32-day ensemble forecasts initialized every Thursday. Additional 61-day ensemble forecasts were performed with 1 June and 1 July 2015 start dates, so as to get a sufficient number of forecasts encompassing the July 2015 heat wave.

In both forecast and re-forecast systems, all the components of the coupled model are initialised as mentioned in Table 1.

The ensembles allow to account for the uncertainty resulting from the initial conditions and from the model errors. They are generated by means of the stochastic dynamics method (Batté and Déqué, 2016). The ensemble size comprises fifteen members for the re-forecast and fifty-one members for the forecast. In order to remove the systematic errors inherent to every prediction system, the forecasts are assessed in terms of anomalies with respect to the climatology of the system. This climatology results from bi-monthly retrospective ensemble forecasts (re-forecast hereafter) computed over the 1993-2014 period.

\subsection{Metrics and reference data}

The ERA-Interim reanalysis (Dee et al., 2011) is used as observational reference in this study for $2 \mathrm{~m}$ daily maximum temperature $\left(T_{\max }\right)$ as well as $500 \mathrm{hPa}$ geopotential height (Z500). Figure 2 shows the observed daily $T_{\max }$ departure from the climatology over France between 20 June and 31 July 2015. The warm spell lasted nearly one month, with two peaks of intensity. The most intense took place during the first days of July and the second one after the 15 July. For the forecast study (Sect. 3.2), we decided to focus on the

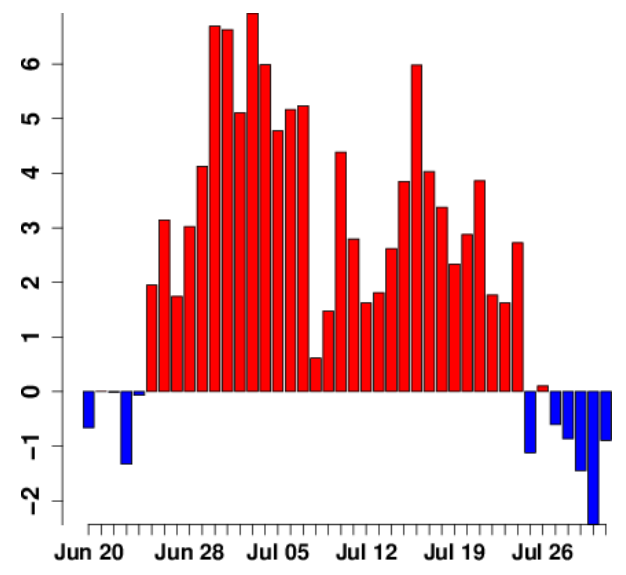

Figure 2. Daily observed $T_{\max }$ anomaly over France.

first peak defined as the averaged $T_{\max }$ value computed temporally over the first 6 days of July and spatially over France. This 6-day spell (6DS) is covered by six successive forecasts issued on 1, 4, 11, 18, 25 June and 1 July 2015.

In our re-forecast evaluation (Sect. 3.1), we consider weekly averaged fields. The first four days of the re-forecast are skipped, so that week 1 is computed as the mean value of the days five to eleven. This empirical method allows to separate the medium range predictability of the first 11 days from the longer range predictability beyond (Vitart, 2004). Such processing provides four full 7-day weeks out of a 32day re-forecast. As mentioned in the previous section, the systematic errors of the model lead to a biased forecast. The biases for weeks 1 to 4 are computed by subtracting observed multi-year weekly means from the corresponding simulated fields.

The predictive skill of the ensemble is assessed by computing at each grid point the Brier skill score (BSS) for $T_{\max }$ exceeding the upper tercile. The Brier score (BS) measures the mean square distance in probability space between the reforecast and reference data for this dichotomous event (Brier, 1950). The BSS then compares BS of the verified re-forecast to a benchmark forecast (here we use the climatology of the re-forecast for each of the 4 weeks). It ranges from $-\infty$ to 1 , with 1 corresponding to a perfect forecast, and positive values where the re-forecast improves with respect to the benchmark.

The biases and BSS computation over Europe relies on the re-forecast initialized 1 and 15 June of the 1993-2014 period.

\section{Results}

\subsection{Bias and skill}

We removed model biases for the assessement of our subseasonal forecasts by performing analyses over anomalies. Yet, biases should not be neglected since they can rapidly 
Table 1. Initial conditions of the CNRM-CM components.

\begin{tabular}{lll}
\hline & Re-forecast & Forecast \\
\hline $\begin{array}{l}\text { Atmosphere and land surface } \\
\text { Ocean and Sea-Ice }\end{array}$ & Era-Interim (Dee et al., 2011) & IFS operational Analyses at 00:00 UTC \\
& Mercator-Ocean GLORYS (Ferry et al., 2010) & Mercator-Ocean operational Analyses \\
\hline
\end{tabular}
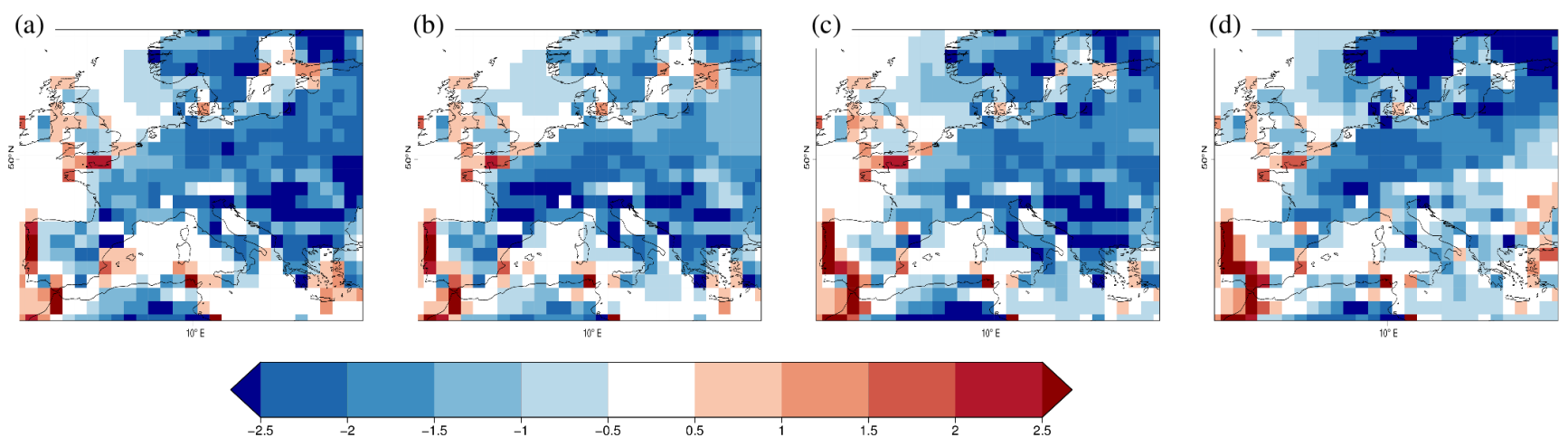

Figure 3. $T_{\max }$ bias (K) for week 1 (a), 2 (b), 3 (c) and 4 (d).
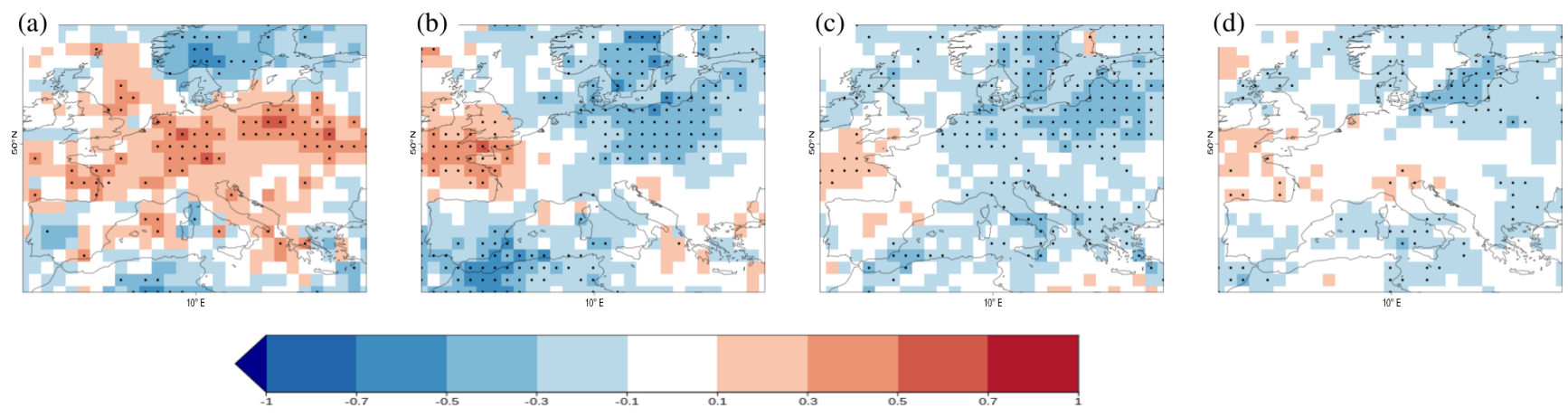

Figure 4. BSS for mean $T_{\max }$ above the upper tercile for week 1 (a), 2 (b), 3 (c) and 4 (d). Stippling indicates significant values with a $95 \%$ confidence level.

degrade the information coming from the initial conditions and hence alter the forecast quality if too pronounced.

The $T_{\max }$ biases are depicted in Fig. 3. They are fairly constant over the 4 weeks of the re-forecast, and predominantly cold over most of continental Europe, except for the westernmost part. They are smaller over the oceans, which is unsurprising since the air temperature over seas evolves more slowly than over land surfaces. Over France, the bias generally ranges between -1 and $-2.5 \mathrm{~K}$ with maximum absolute values during week 2 . This bias, although not negligible, remains small with respect to the amplitude of the temperature anomaly observed during the 2015 event which exceeds $5 \mathrm{~K}$ (Fig. 2).

Figure 4 shows the BSS for weeks 1 to 4 over Europe, for $T_{\max }$. The positive values depicted by red hues indicate the areas where the S2S system is more skilful than climatology. As early as week 2, the skill becomes very marginal and remains as such for weeks 3 and 4 . This result tends to point out a limited added value of our system for the sub-seasonal horizon, at least for $T_{\max }$. However, this metric is computed over a restricted sample of 22 years which contains a limited number of comparably strong events. A larger re-forecast period would allow a better sampling. Additionally, it would allow us to perform a conditional skill study by selecting enough start dates with strong external forcing in the initial conditions, since these may lead to enhanced predictability of a particular extreme event such as in July 2015 (Prodhomme et al., 2016). This point is further discussed in Sect. 4.

\subsection{Anticipation of the 2015 heat wave}

The shapes of simulated and observed $T_{\max }$ distribution over France for 6DS are quite similar (Fig. 5a). However, the median of the simulated distribution is shifted towards colder values by about $1 \mathrm{~K}$ with respect to the reference. This is consistent with the cold bias of the forecast system over France 
(a)

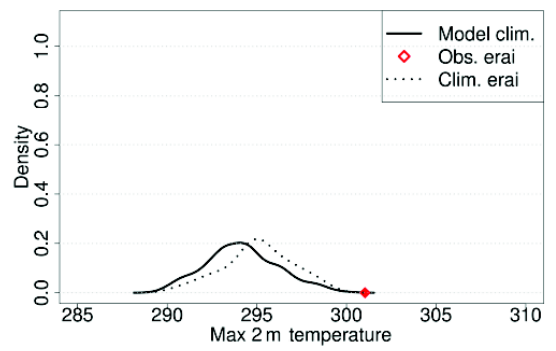

(b)

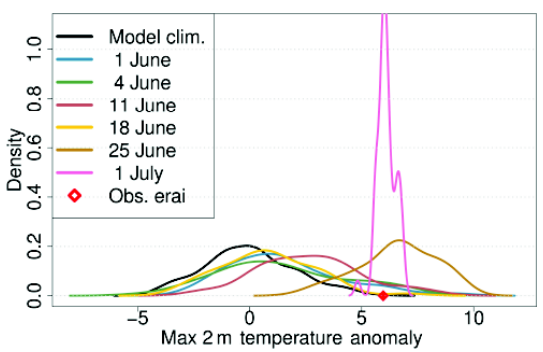

(c)

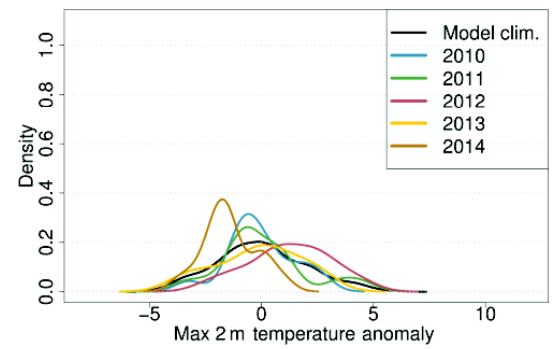

Figure 5. 6DS mean $T_{\max }$ probability density functions over France: model and observed climatologies over 1993-2014 (a), $T_{\text {max }}$ anomalies of successive forecasts for 2015 (b), and recent year re-forecasts initialized on 1 June (c).

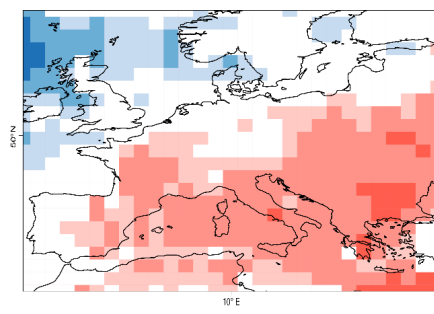

Init June 1

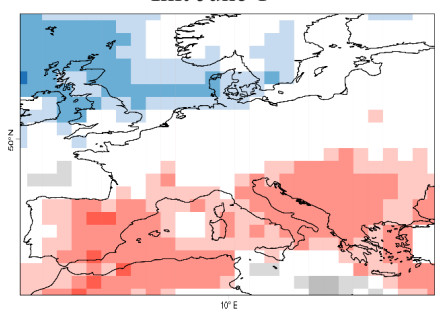

Init June 18

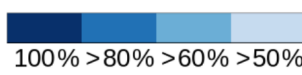

Lower tercile

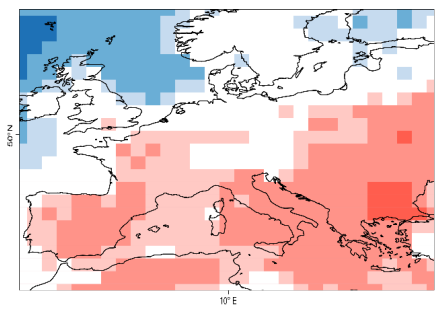

Init June 4

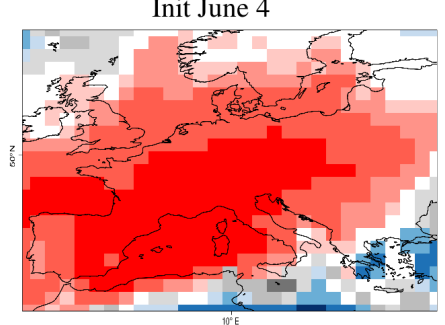

Init June 25

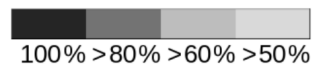

Inter tercile
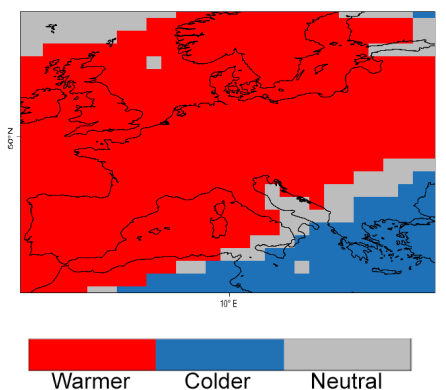

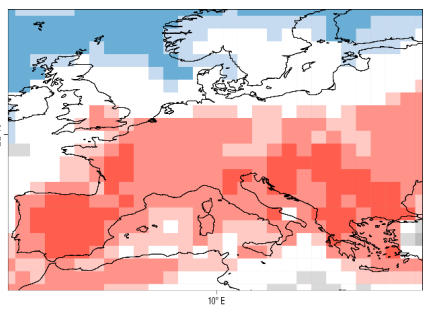

Init June 11

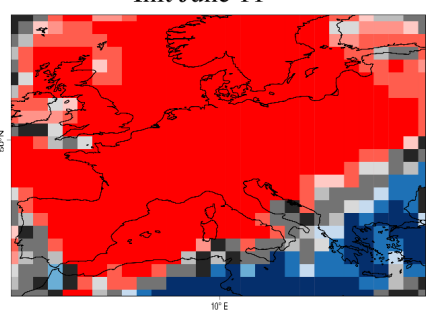

Init July 1

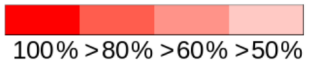

Upper tercile

Figure 6. Probabilty of the most likely 6DS $T_{\max }$ tercile (top rows), observed tercile (bottom).

described in the previous section. The observed event (displayed by the red diamond in this figure) is located towards the end of the upper tail of the distribution, which confirms the rarity of the $T_{\max }$ range observed in July 2015 .

The successive forecasts displayed in color shades (Fig. 5b) show an increasingly sharp distribution for the last two start dates (25 June and 1 July). This was expected since predictive uncertainty diminishes as the event becomes closer to the initial date of the forecast. However, all the forecast distributions are shifted towards warmer values as compared to the climatology of the model, including the forecasts initialized about one month ahead of the event. These shifts are significant with a $95 \%$ confidence, both in mean values (using the Student $t$-test) and in distributions (based on the Wilcoxon-Mann-Whitney test). It can be argued that this is a consequence of the warming trend along the re-forecast pe- 


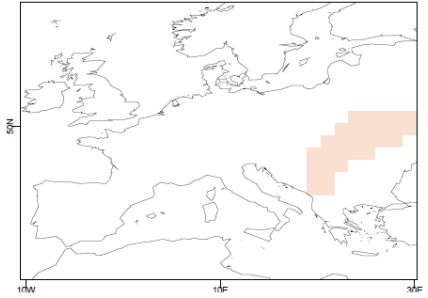

Init June 1

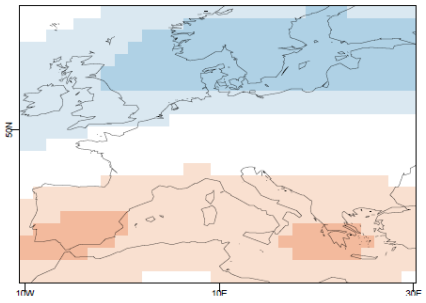

Init June 18

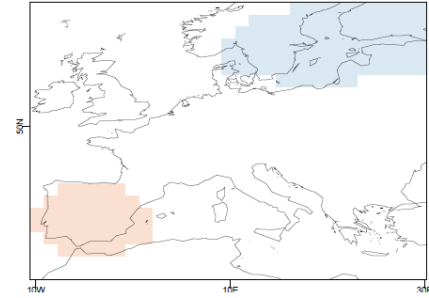

Init June 4

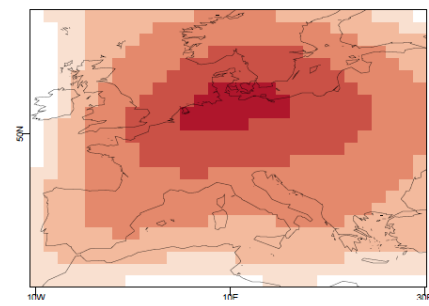

Init June 25

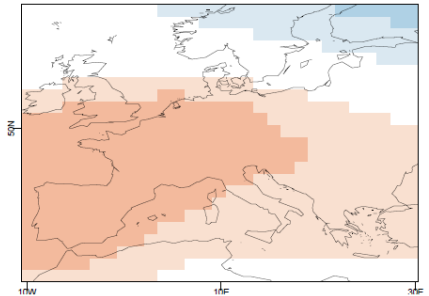

Init June 11

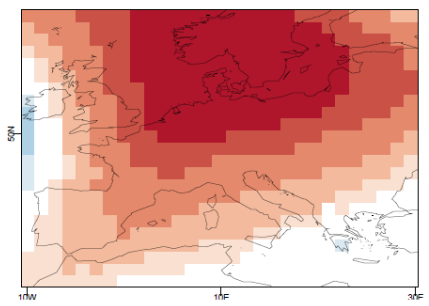

Init July 1
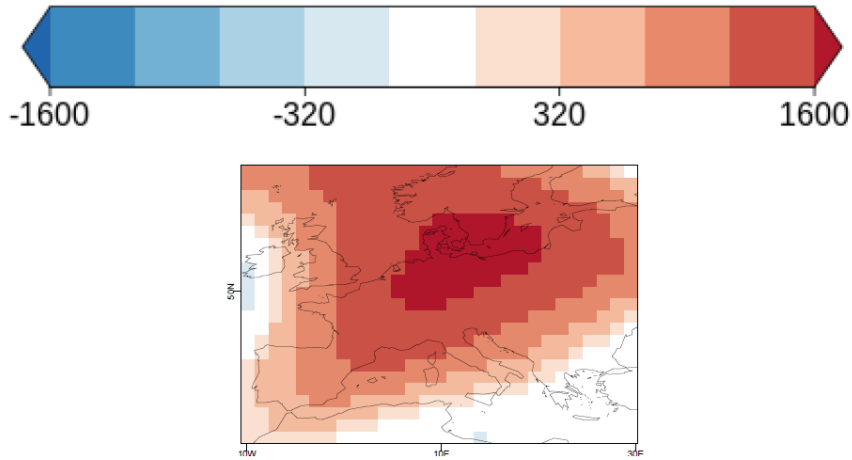

Observation

Figure 7. 6DS Z500 anomaly $\left(\mathrm{m}^{2} \mathrm{~s}^{-2}\right)$ in successive forecasts (top rows) and observation (bottom).

riod, with recent years frequently warmer than the first years. In order to verify this hypothesis, the re-forecast distribution of the years 2010 to 2014 were superimposed to the full model climatology distribution for the time period and region of interest (Fig. 5c). Those five recent years seem equally distributed on either side of the climatological median, which tends to rule out the warming trend effect to explain our results.

A spatial approach of forecast fields is proposed to gain further insight into the predictability of that heat wave. Figure 6 depicts the probability of the most likely tercile for 6DS $T_{\max }$ anomaly for each forecast. It is to be compared with the observed tercile. It can be noticed that a warm signal is already present over southern Europe in the 1 June forecast and tends to persist in the following forecasts. However, except for a few regions such as France, the Iberian Peninsula and the Balkans, this warm pattern remains misplaced until the last two forecasts. Moreover, its amplitude is considerably reduced in the 18 June forecast as compared to the 3 earlier forecasts. The following section discusses a possible cause for these limitations.
Figure 7 shows that unlike $T_{\max }$, the Z500 forecasts do not compare well to the reference data until the last two start dates. Note that the Z500 forecast anomaly (Fig. 7) was rescaled to take into account the dimming effect of ensemble averaging. The re-scaling factor is the ratio $\frac{\sigma_{0}}{\sigma_{\mathrm{f}}}$ where $\sigma_{\mathrm{o}}$ is the standard deviation of the observed Z500 anomalies and $\sigma_{\mathrm{f}}$ the standard deviation of the forecast ensemble mean. The large observed geopotential height positive anomaly only appears in the 25 June forecast onwards. This suggests that the early anticipation of the warm surface pattern over Southern Europe in the forecasts does not result from the large scale atmospheric circulation. The impact of land-surface initial conditions, possibly combined to that of the Mediterranean sea, could thus explain the relative predictability of the first peak of the warm event July 2015 although only a dedicated study could confirm this hypothesis. 


\section{Discussion and conclusions}

This study was the first assessment of the new subseasonalto-seasonal forecast system developed at CNRM through a case study, namely the severe heat wave that struck France and surrounding countries in July 2015. The successive forecasts, issued from early June onwards, consistently predicted a warm surface temperature anomaly over France during the first week of July, corresponding to the most intense stage of that heat wave. Although it is beyond the scope of this work to analyse in depth the factors explaining this relative success, previous seasonal studies showed the influence of anomalous initial conditions in subsequent summer heat waves. For example, sea surface temperature warm anomalies in June 2003 likely contributed to enhance the severity of the following summer heat wave (Feudale and Shukla, 2011a, b) and low soil moisture in spring was revealed as a key ingredient of the 2010 heat wave over Russia (Prodhomme et al., 2016). In 2015, the sea surface temperature of the Mediterranean and Near-Atlantic was not particularly warm in early June, whereas soils were anomalously dry over Western Europe (not shown). Since the CNRM-CM forecast system anticipated the warm surface anomaly to a certain extent but not the simultaneous mid-tropospheric geopotential anomaly, it would be worth testing the relative contribution of land, sea and atmosphere initial conditions in this prediction with a dedicated experimental framework. For example, the conditional skill of S2S systems in predicting West European heat waves would be worth exploring by computing the skill over a sub-sample of re-forecast years with dry or wet soils in initial conditions. Nonetheless, such a study would require a greater number of start dates to be robust. The weaker signal in the forecast issued on 18 June might relate to an excessive sensitivity of our system to soil moisture initial state. Abundant rainfall between 11 and 13 June led to significant soil moistening over Spain and South-West France, which shows in 18 June initial conditions and afterwards. The forecast issued a week later is initialized closer to the targeted event: the predictability stemming from atmospheric initial conditions takes the lead on that provided by slower components of the climate system, thus explaining the improvements found.

The relative success in anticipating this warm event is also counterbalanced by the limited skill of the forecast system beyond the first 12 days following the initial date, at least for that time of year and that region. However, Magnusson et al. (2015) also highlighted a fair anticipation of the same event based on the ECMWF monthly forecasting system. Therefore, the robustness of these results would deserve a more thorough multi-model case study, which would be facilitated by the recent availability of the multi-S2S forecast system database (Vitart et al., 2016).
Data availability. This work is based on S2S data. S2S is a joint initiative of the World Weather Research Programme (WWRP) and the World Climate Research Programme (WCRP). The original S2S database is hosted at ECMWF as an extension of the TIGGE database. The data used for this work can be retrieved following http://apps.ecmwf.int/datasets/data/ s2s-realtime-instantaneous-accum-lfpw/levtype $=$ sfc/type $=\mathrm{cf} / \quad(\mathrm{Vi}-$ tart et al., 2016).

Competing interests. The authors declare that they have no conflict of interest.

Edited by: Á. G. Muñoz

Reviewed by: S. Materia and one anonymous referee

\section{References}

Barbier, J., Guichard, F., Bouniol, D., Couvreux, F., and Roehrig, R.: Spring sahelian heat waves: detection, characteristics and historical trend, J. Climate, submitted, 2017.

Batté, L. and Déqué, M.: Randomly correcting model errors in the ARPEGE-Climate v6.1 component of CNRM-CM: applications for seasonal forecasts, Geosci. Model Dev., 9, 2055-2076, doi:10.5194/gmd-9-2055-2016, 2016.

Brier, G. W.: Verification of forecasts expressed in terms of probability, Mon. Weather Rev., 78, 1-3, 1950.

Brunet, G., Shapiro, M., Hoskins, B., Moncrieff, M., Dole, R., Kiladis, G. N., Kirtman, B., Lorenc, A., Mills, B., Morss, R., Polavarapu, S., Rogers, D., Schaake, J., and Shukla, J.: Collaboration of the weather and climate communities to advance subseasonal-to-seasonal prediction, B. Am. Meteorol. Soc., 91, 1397-1406, 2010.

Dee, D. P., Uppala, S. M., Simmons, A. J., Berrisford, P., Poli, P., Kobayashi, S., Andrae, U., Balmaseda, M. A., Balsamo, G., Bauer, P., Bechtold, P., Beljaars, A. C. M., van de Berg, L., Bidlot, J., Bormann, N., Delsol, C., Dragani, R., Fuentes, M., Geer, A. J., Haimberger, L., Healy, S. B., Hersbach, H., Hólm, E. V., Isaksen, L., Kållberg, P., Köhler, M., Matricardi, M., McNally, A. P., Monge-Sanz, B. M., Morcrette, J.-J., Park, B.-K., Peubey, C., de Rosnay, P., Tavolato, C., Thépaut, J.-N., and Vitart, F.: The ERA-Interim reanalysis: configuration and performance of the data assimilation system, Q. J. Roy. Meteor. Soc., 137, 553-597, doi:10.1002/qj.828, 2011.

Ferry, N., Parent, L., Garric, G., Barnier, B., and Jourdain, N. C.: Mercator global Eddy permitting ocean reanalysis GLORYS1V1: Description and results, Mercator-Ocean Quart. Newsl., 36, 15-27, 2010.

Feudale, L. and Shukla, J.: Influence of sea surface temperature on the European heat wave of 2003 summer. Part I: an observational study, Clim. Dynam., 36, 1691-1703, 2011a.

Feudale, L. and Shukla, J.: Influence of sea surface temperature on the European heat wave of 2003 summer. Part II: a modeling study, Clim. Dynam., 36, 1705-1715, 2011 b.

Lorenz, E.: Deterministic nonperiodic flow, J. Atmos. Sci., 20, 130$141,1963$.

Magnusson, L., Thorpe, A., Buizza, R., Rabier, F., and Nicolau, J.: Predicting this year's European heat wave, 
ECMWF newsletter Number 145, Autumn 2015, available at: http://www.ecmwf.int/sites/default/files/elibrary/2015/ 14589-newsletter-no145-autumn-2015.pdf (last access: 2 May 2017), 2015.

Ouzeau, G., Soubeyroux, J. M., Schneider, M., Vautard, R., and Planton, S.: Heat waves analysis over France in present and future climate: Application of a new method on the EURO-CORDEX ensemble, Climate Services, 4, 1-12, doi:10.1016/j.cliser.2016.09.002, 2016.

Perkins, S. E.: A review on the scientific understanding of heatwaves - their measurement, driving mechanisms, and changes at the global scale, Atmos. Res., 164, 242-267, doi:10.1016/j.atmosres.2015.05.014, 2015.

Prodhomme, C., Doblas-Reyes, F., Bellprat, O., and Dutra, E.: Impact of land-surface initialization on sub-seasonal to seasonal forecasts over Europe, Clim. Dynam., 47, 919-935, doi:10.1007/s00382-015-2879-4, 2016.

Robertson, A., Kumar, A., Peña, M., and Vitart, F.: Improving and Promoting Subseasonal to Seasonal Prediction, B. Am. Meteorol. Soc., 96, ES49-ES53, doi:10.1175/BAMS-D-14-00139.1, 2015.

Schoetter, R., Cattiaux, J., and Douville, H.: Changes of western European heat wave characteristics projected by the CMIP5 ensemble, Clim. Dynam. 45, 1601, doi:10.1007/s00382-014-24348,2014 .
Vitart, F.: Monthly forecasting at ECMWF, Mon. Weather Rev., 132, 2761-2779, doi:10.1175/MWR2826.1, 2004.

Vitart, F., Ardilouze, C., Bonet, A., Brookshaw, A., Chen, M., Codorean, C., Déqué, M., Ferranti, L., Fucile, E., Fuentes, M., Hendon, H., Hodgson, J., Kang, H., Kumar, A., Lin, H., Liu, G., Liu, X., Malguzzi, P., Mallas, I., Manoussakis, M., Mastrangelo, D., MacLachlan, C., McLean, P., Minami, A., Mladek, R., Nakazawa, T., Najm, S., Nie, Y., Rixen, M., Robertson, A. W., Ruti, P., Sun, C., Takaya, Y., Tolstykh, M., Venuti, F., Waliser, D., Woolnough, S., Wu, T., Won, D. J., Xiao, H., Zaripov, R., and Zhang, L.: The Sub-seasonal to Seasonal (S2S) Prediction Project Database, B. Am. Meteorol. Soc., 98, 163-176, doi:10.1175/BAMS-D-16-0017.1, 2016.

Voldoire, A., Sanchez-Gomez, E., Salas y Mélia, D., Decharme, B., Cassou, C., Sénési, S., Valcke, S., Beau, I., Alias, A., Chevallier, M., Déqué, M., Deshayes, J., Douville, H., Fernandez, E., Madec, G., Maisonnave, E., Moine, M. P., Planton, S., SaintMartin, D., Szopa, S., Tyteca, S., Alkama, R., Belamari, S., Braun, A., Coquart, L., and Chauvin, F.: The CNRM-CM5.1 global climate model: description and basic evaluation, Clim. Dynam., 40, 2091-2121, doi:10.1007/s00382-011-1259-y, 2013. 